\title{
Prediction of bed level variations in nonuniform sediment bed channel
}

\author{
B R ANDHARIA, P L PATEL*, V L MANEKAR and P D POREY
}

Department of Civil Engineering, S.V. National Institute of Technology, Surat 395007, India

e-mail: andharia.bhoomi@gmail.com; premlalpate11966@gmail.com; vivek_manekar@yahoo.co.in; prakash.porey@gmail.com

MS received 7 December 2016; revised 1 September 2017; accepted 2 March 2018; published online 12 April 2018

\begin{abstract}
In the present study, a numerical model, based on one-dimensional de Saint-Venant equations along with sediment continuity equation, is developed for prediction of bed levels in non-cohesive sediments in aggrading alluvial channels. One-dimensional, unsteady flow equations and sediment continuity equations are solved using 'shock-capturing', second order accurate, explicit MacCormack finite difference scheme while considering upstream and downstream boundary conditions in the channel. Series of experimental investigations have been undertaken for measurements of bed and water levels in an aggrading channel due to overloading of nonuniform sediments, extracted from the bed of Tapi River at Surat City, in a flume installed in Advanced Hydraulics Laboratory of SVNIT, Surat, India. A satisfactory coupling between the water flow and sediment flow has been achieved. The sediment continuity equation is used for the each size class to compute the volume of each size class after each time step at any computational node in the computational grid. The fractional bed and suspended load transport capacities for different size fractions have been computed using fractional transport laws for nonuniform sediments. The active bed layer concept has been implemented in finite difference scheme to consider the interaction and exchange of sediment and water flow near the mixing layer. The performance of developed numerical model has been satisfactorily verified with independent experimental data of nonuniform sediment bed. Also, consideration of sediment nonuniformity in computation of bed level variation has been demonstrated by comparing the results based on sediment transport functions of uniform and nonuniform sediments.
\end{abstract}

Keywords. Numerical model; aggradation; non-cohesive sediment mixture; active bed layer; fractional sediment transport.

\section{Introduction}

Natural rivers are invariably alluvial in nature. The catchment of river systems supply enormous amount of sediments into the rivers. Prediction of aggradation and/or degradation and changes in the plan forms of alluvial rivers still has been a subject of active research. The bed level variations in alluvial streams can be predicted using analytical or numerical approaches. The existing analytical models for prediction of aggradation and degradation are based on gross assumptions, and their applicability is limited to very simplified cases only. In recent years, numerical models have been found favorite for solving the problem wherein partial differential equations of fluid flow and sediments are discretized to obtain their corresponding algebraic equations in space-time domain. The solutions of discretized algebraic equations gives bed levels along the channel at desired time intervals. The numerical models are coupled, semi-coupled and uncoupled in nature. The semi coupled models are the desired option

*For correspondence wherein flow calculations are decoupled from sediment calculations, however, three components of sediment module, viz. sediment transport, bed level changes and material sorting, are solved in the coupled manner. The leading studies on semi-coupled models are Rahuel et al. [1], Holly et al. [2], Saiedi [3], Kassem and Chaudhry [4], Cao et al. [5], Ferguson and Church [6] and Termini [7, 8]. Further, sediments in natural rivers are nonuniform in nature. The sediments can be considered as nonuniform, if the geometric standard deviations $\left(\sigma_{\mathrm{g}}\right)$ of bed material is more than 1.4 [9]. Implementation of nonuniform sediment transport models in the numerical scheme in computation of bed level, is expected to give better results in bed levels variations of alluvial channels.

Borah et al. [10] developed a 1D uncoupled numerical model for simulating the well-graded, non-cohesive sediments in relatively stable channel geometries with negligible out-of-bank transport and transverse currents. The effect of particle exchange between sediment load and bed layer was simulated by introducing 'Active layer' in the mixing zone. The algorithm was developed using simple 
kinematic wave equations for water flow. The model was validated using the experimental flume data of Ashida and Michiue [11] and data from field investigations (Luis Valley Canal, Colorado, and the East Fork River, Wyoming). Lyn [12] and Lyn and Goodwin [13] proposed the mathematical features of mobile-bed flow equations and suggested strong justification for the coupled approach. Lyn [12] aimed at investigating the coupling of flow and sediment variables for rapid varied flow in water and sediment discharges applied at upstream boundary; and emphasised the need of replacing 'mean velocity' with 'water discharge' in the governing equations of water and sediment phase for better representation of upstream boundary condition. A fully-coupled 1D mobile-bed model (CARICHAR) was introduced by Rahuel et al. [1] using implicit Preissmann finite difference scheme for prediction of water and bed levels in alluvial streams for unsteady flow conditions. The developed model was tested using the data of lower Rhône River in France. The developed model considered the rate of bed load transport using uniform sediment function, viz. Meyer-Peter-Muller [14] equation. The study concluded that mobile bed processes have significant effects on the flow field through effective roughness, and, thus, strong physical coupling is required in solving water and sediment equations. Holly and Rahuel $[15,16]$ developed a 1D fully coupled mobile bed model based on use of shallow water equations and treatment of highly nonuniform sediments while recognizing the need of spatial-lag transport law for bed load using implicit numerical solutions of governing partial differential equations. Alcrudo et al. [17] compared the performance of three numerical schemes, namely, Roe-Sweby scheme, MacCormack scheme and Lax-Friedrichs scheme; and it was concluded that MacCormack scheme does not exhibit unphysical jump or spurious oscillation, and can be used in computational hydraulics as it is easy to apply, simple to use, performance is better and effective in computational cost. However, introduction of artificial viscosity term was recommended for stability of MacCormack scheme. Correia et al. [18] presented a fully coupled (FCM) 1D bed level variations model capable for the prediction of sediment transport and bed levels under unsteady flow conditions. The system of governing equations was explicitly coupled by introducing a term representing the rate of change of bed level in the continuity equation of water phase. Cui et al. [19] developed a 1D uncoupled numerical model for bed level variations in aggrading channels and compared the results with coupled models for rapid varied flow and Froude number close to unity in a uniform sediment bed. The good agreement between the two models suggested that concern in the literature about the use of uncoupled models may have been overstated. Saiedi [3] developed a 1D coupled numerical model called COUPFLEX using implicit Pressmann scheme, and compared the results with uncoupled model. The results were compared with experimental flume data of Saiedi [20]. While comparing the output from the model, it was concluded that accuracy gained due to coupling of water routing and sediment continuity equation is often less than resulting loss due to inappropriate use of empirical equilibrium sediment transport equations. Kassem and Chaudhry [4] showed that semi-coupled models are not always unstable and give predictions comparable to the coupled models. Singh et al. [21] developed a 1D fully coupled numerical model using implicit Preissmann finite deference scheme for simulating aggradation processes in alluvial channel with uniform and nonuniform sediment beds. They used sediment transport functions of uniform and nonuniform sediments for bed load and suspended load transport rates separately. The validation of developed bed level variations model was carried out using experimental data reported in literature [11], and field data of Creek Dike failure of year 1988-1989 in Utah, USA for uniform and nonuniform sediments, respectively. Cao et al. [5] studied a 1D shallow water hydrodynamic model for dam break hydraulics over an erodible sediment bed, and emphasized the need for calibration of sediment bed roughness and sediment transport relationships. Wu et al. [22] proposed a 1D depth-integrated uncoupled numerical model using Preissmann's implicit scheme for the prediction of sediment transport, bed level variations, and bed-material sorting in different field conditions including aggradation processes. Sensitivity analysis of implicit and explicit schemes for bed-material sorting revealed that implicit scheme is more stable and less sensitive to fractional bed deformation or changes. The model was tested for the field data of Pa-Chang River in South Taiwan and Goodwin Creek watershed channels in Mississippi, and the results were found in close agreement with field measurements. Pontillo et al. [23] validated a 1D numerical code, based on shallow-water equations coupled with a sediment erosion code, was applied to an unsteady two-phase flow for trapezoidal-shaped sediment dike due to breaching from overtopping. The numerical results are compared with three tests of laboratory experiments and found satisfactory. Termini [8] developed a 1D semi-coupled numerical model using FDM for computation of the river bed level variations in non-equilibrium conditions. The model could also be used for computation of bed load and suspended load transport rates separately. The stability and convergence criteria for their proposed numerical scheme were suggested as $0.01 \leq \Delta x / L \leq 0.10$ and $\Delta t / T \leq 0.05$. Here, $\mathrm{L}$ is length of spatial domain and $\mathrm{T}$ is the time scale of transient process.

In previous studies, uncoupled numerical models, were reported to be less accurate and unstable, and coupled models were found to be time consuming due to excessive computational efforts in prediction of bed level variations in aggrading channels, especially, while considering fractional sediment transport for different size classes. Under such circumstances, the semi-coupled numerical model is required to be investigated using 'active bed layer' concept for computation of bed levels in nonuniform sediment beds. 
The leading studies on semi-coupled models indicated that 1D semi-coupled finite difference models could be an effective approach in estimation of bed levels of alluvial streams [22]. Also, as per information to authors, two steps predictor-corrector MacCormac numerical scheme had not been used by the previous investigators in prediction of bed level of aggrading channels with nonuniform sediment beds. In the present study, a numerical model, based on de Saint-Venant equations and Exner's sediment continuity equation, is developed for prediction of bed and water levels in aggrading alluvial channels with noncohesive nonuniform sediment bed. One-dimensional, unsteady flow equations and sediment continuity equations for different size classes are solved using 'shock-capturing', second order accurate, explicit MacCormack finite difference scheme while considering appropriate upstream and downstream boundary conditions in the channel. Series of experimental investigations have been undertaken for measurements of bed and water levels in an aggrading channel due to overloading of non-cohesive sediment mixture. The fractional bed and suspended load transport capacities for different size fractions have been computed using fractional sediment transport laws for nonuniform sediments channel bed. The active bed layer concept has been implemented in finite difference scheme to consider the interaction and exchange of sediment and water flows near the mixing layer. The performance of developed numerical model has been satisfactorily verified with independent experimental data of nonuniform sediment bed. Also, the performance of numerical model in prediction of bed level using nonuniform sediment transport factions and uniform sediment function have been demonstrated for the data of sediment bed.

\section{Model descriptions}

\subsection{Governing equations}

In the proposed numerical scheme, governing equations for mass and momentum balance of water and sediment phases are solved simultaneously using explicit finite difference approximation to predict the evolution of the bed level with time due to aggradation in fluvial streams. The basic onedimensional partial differential equations describing unsteady free surface flow in a wide rectangular alluvial channel, with no lateral discharge, as suggested by [24], can be expressed as:

$$
\text { Continuity equation for water } \frac{\partial q}{\partial x}+\frac{\partial h}{\partial t}=0
$$

Momentum equation for water $\frac{\partial q}{\partial t}+\frac{\partial}{\partial x}\left(\frac{q^{2}}{h}+\frac{1}{2} g h^{2}\right)$

$$
+g h \frac{\partial z}{\partial x}+g h S_{f}=0
$$

Continuity equation for sediment $\frac{\partial}{\partial t}\left[(1-p) z+\frac{q_{T} h}{q}\right]$

$$
+\frac{\partial q_{T}}{\partial x}=0
$$

where, $q=$ water discharge per unit width, $h=$ flow depth, $z=$ bed elevation, $q_{T}=$ equilibrium sediment discharge per unit width of channel, $g=$ acceleration due to gravity, $S_{f}=$ friction slope, $x=$ distance along the channel, $t=$ time and $p=$ porosity of bed layer.

Equations (1-3), in its equivalent vector form, can be expressed as

$$
\begin{aligned}
& \mathbf{U}=\left[\begin{array}{l}
h \\
q \\
z+\frac{q_{T} h}{q(1-p)}
\end{array}\right], \mathbf{F}=\left[\begin{array}{l}
q \\
\frac{q^{2}}{h}+\frac{1}{2} g h^{2}+g h z \\
\frac{q_{T}}{(1-p)}
\end{array}\right], \\
& \mathbf{S}=\left[\begin{array}{l}
0 \\
\left(-g h S_{f}\right) \\
0
\end{array}\right]
\end{aligned}
$$

where, dependent variable vector $(\mathbf{U})$, flux vector $(\mathbf{F})$, and source term vector $(\mathbf{S})$.

The friction slope, $S_{f}$, in Eq. (2), is determined using resistance law, viz, Manning's equation, for wide rectangular channel as

$$
S_{f}=\frac{q^{2} n^{2}}{h^{3.333}}
$$

Here, $n$ is Manning's roughness coefficient of the channel bed, depends on characteristics of channel bed surface, and computed from Strickler's equation. The sediment load for nonuniform sediments $q_{T}$, in present study, have been estimated using fractional transport laws for bed load and suspended load for different size classes given by Patel and Ranga Raju [25] and Samaga et al. [26, 27], respectively.

The set of partial differential Eqs. (1)-(3) link three unknown dependent variables $h, q, z$ with the independent variables $x$ and $t$.

\subsection{Numerical scheme}

In the present study, unknown dependent variables like flow depth, unit flow discharge, fractional sediment transport for different size classes and bed levels have been computed using explicit finite difference numerical scheme (MacCormack scheme) with the boundary conditions described in Sect. 2.9 for known independent variables $x$ and $t$. The coupling between hydraulic equations and sediment continuity equations has been achieved using MacCormack scheme, which enables the simultaneous solution of the de SaintVenant-Exner equations with two step predictor-corrector approach. The MacCormack, predictor-corrector scheme, is 
second order accurate in space and time, and able to capture the 'shock', i.e., it is able to describe discontinuities due to steep moving slopes, and, thus, very stable and suitable for aggradation processes [28, 29]. The finite difference grid used in foregoing numerical scheme is shown in figure 1.

The methodology for the implementation of numerical scheme for the bed level variations modeling in aggrading channels, comprising of nonuniform sediments, is shown in flowchart, see figure 2 . In figure 2, superscripts $*$ and $* *$ refer to the values of the dependent variables after the predictor and corrector steps, respectively at unknown time $k+1$ level; suffix ' $o$ ' stands for initial values; $i$ denotes the space node; while $k$ denotes the time node; $B_{o}=$ width of channel; $L=$ length of the channel; $\Delta q_{T}=$ change in sediment discharge; $t_{\text {last }}$ denotes last computational step; $\Delta t=$ temporal step(s); $\Delta x=$ spatial step $(\mathrm{m}) /$ distance increment and $C_{n}=$ Courant number. In $U_{i}^{k+1}$, the subscript $k+1$ is the value at the unknown time level $t+\Delta t$ and subscripts $*$ denotes the predicted value at the unknown time line $k+1$. The vector $\mathbf{U}$ must be discretized in Eq. (4) to calculate the predictor of dependent variables $h, q$ and $z$ at the time level $t+\Delta t$ at $i^{\text {th }}$ computational node.

For stability of the numerical scheme, minimum $\Delta t$ were computed dynamically after every time step using CourantFriedrichs-Lewy (CFL) condition [30], which can be expressed as

$$
C_{n}=\frac{(q / h+\sqrt{g h}) \Delta t}{\Delta x} \leq 1
$$

The minimum values of $\Delta t$ from Eq. (6) were arrived using computed flow parameters along previous time line ( $k^{\text {th }}$ time line), for using the same for computation along current time, $(k+1)$ time line.

\subsection{Fractional sediment transport laws for nonuniform sediments}

Invariably, natural stream beds consist of nonuniform sediments. The sediment transport rates for such stream are estimated by summing up sediment transport rates of individual size fraction for known hydraulic and sediment characteristics. In numerical scheme, proposed in the present study, fractional rates of bed load and suspended load transport for each size class were estimated using Patel and Ranga Raju [25] and Samaga et al. [26, 27], respectively. The total sediment transport rates were then estimated by summing up the fractional bed load and suspended load for all size fractions computed above. The variation in particle size composition with time and space for each computational node were computed using the procedure described in the following paragraphs.

\subsection{Thickness of active bed layer}

The mixing zone of sediment remaining in contact with the flow is referred as active layer (ABL). The thickness and particle size distribution of ABL can vary throughout the computation, however, the layer is assumed to be homogeneous within itself at any given point of time. The bed material below the active layer is termed as substrate. In the past studies, the thickness of active layer was considered as function of depth of flow [1] and particle size [10]. Here, both the approaches have been combined for computation of thickness of active layer as [21],

$$
T_{b}=d_{90}+0.3 h\left(1-\frac{\tau_{0 c}}{\tau_{0}}\right)
$$

Here, $d_{90}$ is representative size in the bed material such that $90 \%$ fractions, by weight, are finer than this size, $\tau_{\mathrm{oc}}=$ critical shear stress; and $\tau_{\mathrm{o}}=$ mean shear stress. In dune regime, the flow depth has predominant effect on ABL thickness while particle size plays important role under plane bed condition. Initially, the mixing zone was assumed to be homogeneous in composition. The thickness of ABL $\left(T_{b}\right)$ at each computational node for a given time line can be estimated using Eq. (7).
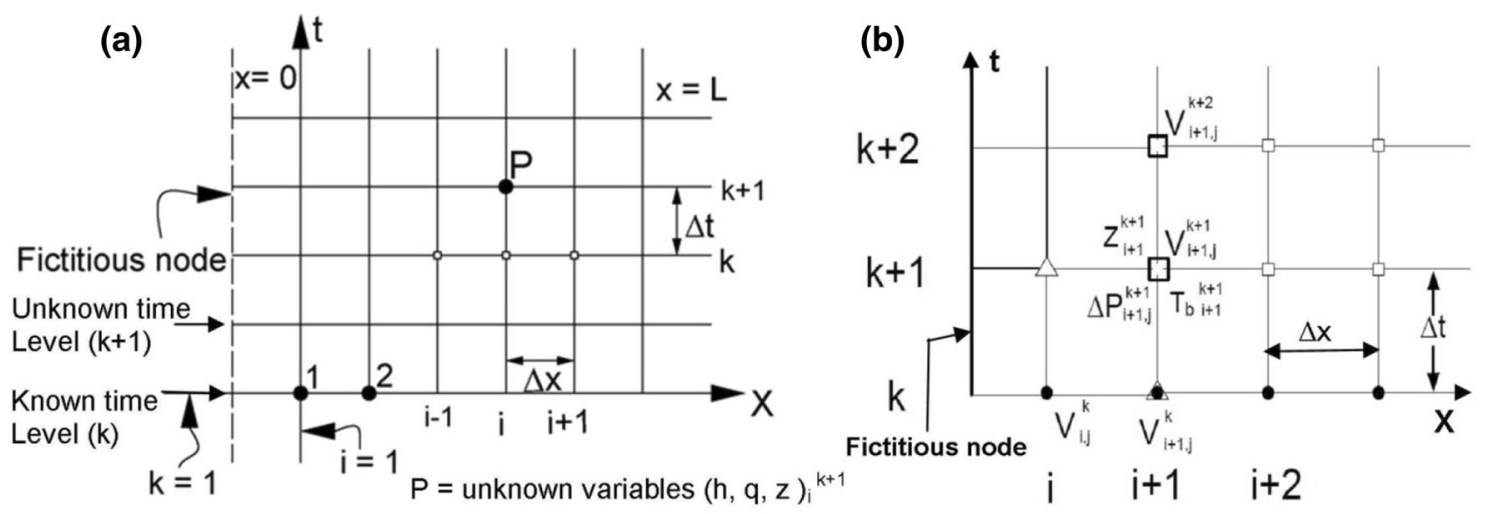

Figure 1. Finite difference grid for MacCormack scheme showing the unknown variables. 


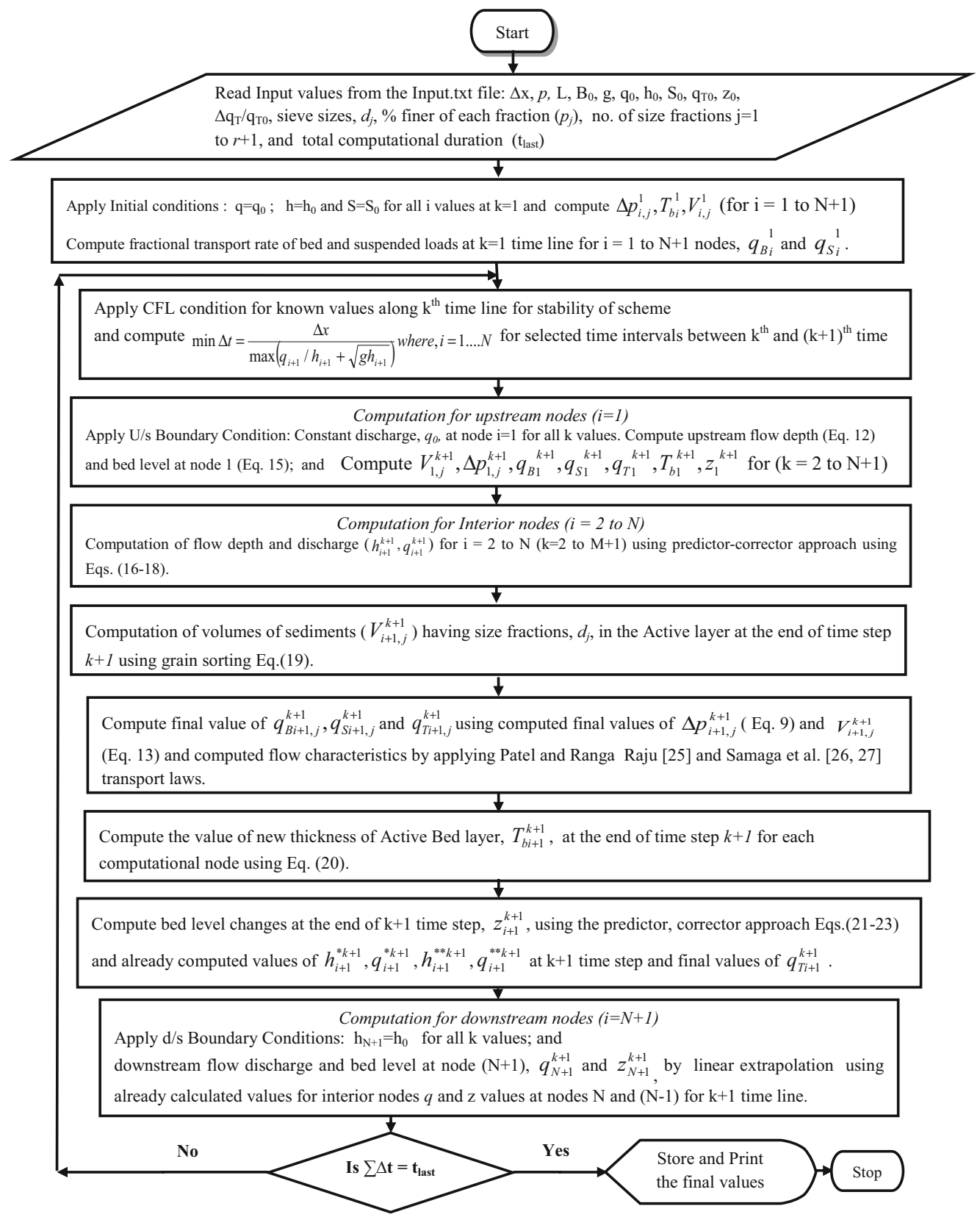

Figure 2. Methodology for development of bed level variations model of aggrading channel (nonuniform sediments bed).

Total volume of any particle size, $d_{j}$, present in the ABL in $\Delta x$ length of the channel, at $i^{\text {th }}$ space node and $k^{\text {th }}$ time line can be expressed as

$$
V_{i, j}^{k}=T_{b i}^{k} B_{0} \Delta x(1-p)\left(\Delta p_{i, j}^{k} / 100\right)
$$

In Eq. (8), $\Delta p_{j}$ is the percentage of sediment size fraction, $d_{j}$, in the $A B L$. The percentage of the sediment of the $j^{\text {th }}$ size fraction in the ABL at the $k^{\text {th }}$ time step for each computational node, $\Delta p_{i, j}^{k}$, is calculated using Eq. (9). Here, $r$ represents total number of size fractions in sediment mixture.

$$
\Delta p_{i, j}^{k}=\frac{V_{i, j}^{k}}{\sum_{j=1}^{j=r+1} V_{i, j}^{k}}
$$

\subsection{Input parameters of the proposed scheme}

The required space interval in computational grid $(\Delta x)$, porosity of bed material $(p)$, length $(L)$ and width $\left(B_{0}\right)$ of channel, initial uniform flow discharge $\left(q_{0}\right)$, flow depth 
$\left(h_{0}\right)$, bed slope $\left(S_{0}\right)$, initial bed level at upstream boundary $\left(z_{0}\right)$, ratio of increased rate of sediment discharge to rate of equilibrium sediment discharge $\left(\Delta q_{T} / q_{T 0}\right)$, grain size distribution of bed material ( $\%$ finer, $p_{j}$, of each sizes, $d_{j}$,), total number of size fractions, and total computational duration, in seconds, are the input parameters of the present scheme.

\subsection{Initial conditions}

Initially (for $k=1$ time line), flow depth, discharge and bed slope at all computational node $(\mathrm{i}=1$ to $\mathrm{N}+1$ ) over the length of channel were considered uniform. Also, it is assumed that initial bed material composition is constant along the depth, width and length of channel. Thus, parameters $d_{90}, h$ and $\tau_{0 c} / \tau_{0}$ are known, initially, along the length of the channel.

Initially, thickness of active bed layer and volume of individual size fractions in active bed layer (ABL) are computed as

$$
\text { Computation of } \begin{aligned}
T_{b i}^{1} \text { for } i & =1 \text { to } N+1 \text { for } k=1: T_{b i}^{1} \\
& =\left(d_{90}\right)_{i}^{1}+0.3 h_{i}^{1}\left(1-\frac{\tau_{0 c}}{\tau_{0}}\right)_{i}^{1}
\end{aligned}
$$

$$
\text { Computation of } \begin{aligned}
V_{i, j}^{1} \text { for } i & =1 \text { to } N+1 \text { for } k=1: V_{i, j}^{1} \\
& =T_{b i}^{1} B_{0} \Delta x(1-p)\left(\Delta p_{i, j}^{1} / 100\right)
\end{aligned}
$$

The $\Delta p_{i, j}^{1}$ values of individual size fraction are computed using Eq. (9) for $k=1$.

\subsection{Computation of time interval for the stability of the scheme}

The minimum value of $\Delta t$ along current time line $(k+1)$ is computed for entire length ( $i=1$ to $\mathrm{N}+1)$ using Eq. (6), while using computed flow parameters $\left(h_{i}^{k}, q_{i}^{k}\right)$ along previous time line (initially, $k=1$ time line).

\subsection{Upstream boundary conditions}

The water discharge $\left(q_{0}\right)$ is considered constant at upstream node $(i=1)$. The flow depth at upstream node was estimated from continuity equation of water using explicit forward difference scheme Eq. (1) as

$$
h_{1}^{k+1}=h_{1}^{k}-\frac{\Delta t}{\Delta x}\left[q_{2}^{k}-q_{1}^{k}\right]
$$

Total volume of sediment particle of $j^{\text {th }}$ size fraction at upstream node $(i=1)$ were computed using Eq. (13) at different time lines as

$$
\begin{aligned}
V_{1, j}^{k+1}= & V_{1, j}^{k}+\Delta t B_{0}\left[q_{T i n, j}-\left(q_{T 1, j}^{k}\right)\right] \\
& +\Delta x B_{0}\left[\left(\frac{q_{T 1, j}^{k} h_{1}^{k}}{q_{1}^{k}}\right)-\left(\frac{q_{T 1, j}^{k+1} h_{1}^{k+1}}{q_{1}^{k+1}}\right)\right]
\end{aligned}
$$

Equation (13) is valid for second time line $(k=2)$ onwards till it reaches the last time step; $q_{\text {Tin }}=\left(q_{T 0}\right.$ $\left.+\Delta q_{T}\right) ; q_{T 0}=\sum q_{T i, j}^{1} ; \quad q_{T i, j}^{1}=q_{B i, j}^{1}+q_{S i, j}^{1} ; \quad q_{B i, j}^{1}$ and $q_{S i, j}^{1}$ represent fractional rates of bed and suspended load transport for $j^{\text {th }}$ size fraction along $k=1$, i.e., initial condition. As stated earlier, the fractional bed load and suspended loads were computed using Patel and Ranga Raju [25] and Samaga et al. [26, 27] methods, respectively. The solution of Eq. (13) requires trial and error procedure. In first step, initial value of $q_{T 1, j}^{k+1}$ is assumed to be the same as $q_{T 1, j}^{k}$, and the value of $V_{1, j}^{k+1}$ is computed from Eq. (13). The values of $V_{i, j}^{k+1}$, using above procedure, are computed for all size fractions. Then, Eq. (9), is used to compute the percentage of each size fraction in the ABL. Thus, knowing the refined values of bed material composition at $k=2$, the fractional transport rates $q_{T 1, j}^{k+1}$ are computed for each size fraction. The computed values of $q_{T 1, j}^{k+1}(\mathrm{k}=1)$ are used in Eq. (13) to get the refined values of $V_{1, j}^{k+1}$. In the present study, standard Newton-Raphson method was used to reduce the number of trials. The values of $V_{1, j}^{k+1}$, is taken as the final, as and when the residual error $(\varepsilon)$ was reached to 0.0001 .

After getting the refined value of $V_{1, j}^{k+1}$ and $\Delta p_{i, j}^{k+1}$, the thickness of ABL, $T_{b 1}^{k+1}$, was computed using Eq. (8) as

$$
T_{b 1}^{k+1}=\frac{V_{1, j}^{k+1}}{B_{0} \Delta x(1-p)\left(\Delta p_{1, j}^{k+1} / 100\right)}
$$

Subsequently, the bed levels at $\mathrm{i}=1$ at different time levels were calculated as

$$
\begin{aligned}
z_{1}^{k+1}= & z_{1}^{k}+\frac{1}{(1-p)}\left[\left(\frac{q_{T} h}{q}\right)_{1}^{k}-\left(\frac{q_{T} h}{q}\right)_{1}^{k+1}\right] \\
& +\frac{1}{(1-p)} \frac{\Delta t}{\Delta x}\left[\left(q_{T 0}+\Delta q_{T}\right)-\left(q_{T}\right)_{1}^{k}\right]
\end{aligned}
$$

\subsection{Computation at interior nodes}

The flow depth and flow discharge $\left(h_{i+1}^{k+1}, q_{i+1}^{k+1}\right)$ at node $i=2$ to $\mathrm{N}$ (for $\mathrm{k}=2$ to $\mathrm{N}$ ) were computed using the predictor-corrector approach described in preceding section. The step-wise procedure for computation of bed level variations is described in the following paragraphs:-

(i) Compute predictor $U_{i}^{* k+1}(h, q)$ values for interior nodes approximated by forward finite difference discretization using their known values from previous computation as given in Eq. (16).

$$
U_{i}^{* k+1}=U_{i}^{k}-\frac{\Delta t}{\Delta x}\left(F_{i+1}^{k}-F_{i}^{k}\right)+\Delta t S_{i}^{k}
$$


(ii) Compute corrector $U_{i}^{* * *+1}(h, q)$ values for interior nodes approximated by backward finite difference discretization using their respective values from predictor stage as given in Eq. (17).

$$
U_{i}^{* * k+1}=U_{i}^{* k+1}-\frac{\Delta t}{\Delta x}\left(F_{i}^{* k+1}-F_{i-1}^{* k+1}\right)+\Delta t S_{i}^{* k+1}
$$

(iii) Compute final values of $U_{i}^{k+1}(h, q)$ at time level $k+1$ for interior nodes as in Eq. (18).

$$
U_{i}^{k+1}=\frac{1}{2}\left(U_{i}^{* k+1}+U_{i}^{* * k+1}\right)
$$

The composition of the active bed layer is altered due to varying transport rates of the individual size classes with time in the channel bed. The estimation of varying composition of active bed layer is dealt as per Borah et al. [10] approach. The grain sorting equation for different size classes which has derived from Exner's sediment continuity equation, is applied at each computational node to compute the total volume of each size class $\left(d_{j}\right)$ present in active layer (as in figure 1),

$$
\begin{aligned}
V_{i+1, j}^{k+1}= & V_{i+1, j}^{k}+\Delta t B_{0}\left[q_{B i, j}^{k}+q_{s i, j}^{k}-q_{B i+1, j}^{k}-q_{s i+1, j}^{k}\right] \\
& +\Delta x B_{0}\left[\left(\frac{q_{T i+1, j}^{k} h_{i+1}^{k}}{q_{i+1}^{k}}\right)-\left(\frac{q_{T i+1, j}^{k+1} h_{i+1}^{k+1}}{q_{i+1}^{k+1}}\right)\right]
\end{aligned}
$$

Equation (19) is valid for second time line onwards till it reaches the last time step; In Eq. (19), $q_{T i+1, j}^{k}=q_{B i+1, j}^{k}+$ $q_{S i+1, j}^{k} ; \quad q_{T i+1, j}^{k+1}=q_{B i+1, j}^{k+1}+q_{S i+1, j}^{k+1} ; \quad q_{B i+1}^{k+1}=\sum_{j=1}^{r+1} q_{B i+1, j}^{k+1} ;$ $q_{S i+1}^{k+1}=\sum_{j=1}^{r+1} q_{S i+1, j}^{k+1} ; \quad q_{B i, j}^{k}=\sum_{j=1}^{r+1} q_{B i, j}^{k} ; \quad q_{S i, j}^{k}=\sum_{j=1}^{r+1}$ $q_{S i, j}^{k} ; q_{B i, j}^{k}, q_{S i, j}^{k}$ and $q_{B i+1, j}^{k+1}, q_{T i+1, j}^{k+1}$ represent fractional rates of bed and suspended load transport $j^{\text {th }}$ size fraction at $i^{\text {th }}$ and $(i+1)^{\text {th }}$ nodes and $k$ and $(k+1)$ time lines, respectively. $V_{i+1, j}^{k}, h_{i+1}^{k}, q_{i+1}^{k}$ and $V_{i+1, j}^{k+1}, h_{i+1}^{k+1}, q_{i+1}^{k+1}$ represent total volume for each size class $\left(d_{j}\right)$ present in active layer, depth of flow and flow discharge at $(i+1)^{\text {th }}$ nodes and $k$ and $(k+1)$ time lines, respectively. The solution of Eq. (19) requires trial and error procedure. In first step, initial value of $q_{T i+1, j}^{k+1}$ are assumed to be same as $q_{T i+1, j}^{k}$ and the value of $V_{i+1 j}^{k+1}$ are computed. The values of $V_{i+1, j}^{k+1}$, using above procedure, are computed for all size fractions. Then, Eq. (9), is used to compute the percentage of each size class in the active layer. Thus, knowing the refined values of bed material composition, the fractional transport rates $q_{T i+1, j}^{k+1}$ are computed for each size fractions at selected node. The computed values of $q_{T i+1, j}^{k+1}$ are used in Eq. (19) to get the refined values of $V_{i+1, j}^{k+1}$. The standard Newton-Raphson method was applied in the present study, to reduce the number of trials. The values of $V_{i+1, j}^{k+1}$ were taken as the final, as and when the residual error $(\varepsilon)$ was reached to 0.0001 .

After getting the refined value of $V_{i+1, j}^{k+1}$, the thickness of active bed layer, $T_{b i+1}^{k+1}$, was computed using Eq. (8) as

$$
T_{b i+1}^{k+1}=\frac{V_{i+1, j}^{k+1}}{B_{0} \Delta x(1-p)\left(\Delta p_{i+1, j}^{k+1} / 100\right)}
$$

Subsequently, the bed levels at interior nodes at any time step were calculated using predictor-corrector approach for already computed values of $h_{i+1}^{*}, q_{i+1}^{*}, h_{i+1}^{* *}, q_{i+1}^{* *}$ at $k+1$ time step and final values of $q_{T i+1}^{k+1}$ (calculated using final values of $V_{i+1}^{k+1}$ and $\Delta p_{i+1}^{k+1}$ ) as

$$
\begin{aligned}
z_{i+1}^{*}= & z_{i+1}^{k}+\frac{1}{1-p}\left[\left(\frac{q_{T} h}{q}\right)_{i+1}^{k}-\left(\frac{q_{T} h}{q}\right)_{i+1}^{*}\right] \\
& -\frac{\Delta t}{(1-p) \Delta x}\left[q_{T i+2}^{k}-q_{T i+1}^{k}\right] \\
z_{i+1}^{* *}= & z_{i+1}^{*}+\frac{1}{1-p}\left[\left(\frac{q_{T} h}{q}\right)_{i+1}^{*}-\left(\frac{q_{T} h}{q}\right)_{i+1}^{* *}\right] \\
& -\frac{\Delta t}{(1-p) \Delta x}\left[q_{T i+1}^{*}-q_{T i}^{*}\right]
\end{aligned}
$$

Finally, the bed levels at any time line $(k+1)$ at interior node ( $\mathrm{i}=2$ to $\mathrm{N}$ ), $z_{i+1}^{k+1}$, are calculated using Eq. (23) as

$$
z_{i+1}^{k+1}=\frac{1}{2}\left(z_{i+1}^{*}+z_{i+1}^{* *}\right)
$$

\subsection{Downstream boundary conditions}

The discharge $\left(q_{N+1}^{k+1}\right)$ and bed levels $\left(z_{N+1}^{k+1}\right)$ are estimated by linearly extrapolating the values from interior nodes, i.e., $\mathrm{N}$ and $\mathrm{N}-1$, for $(k+1)$ time line as

$$
\begin{aligned}
q_{N+1}^{k+1} & =\left[\left(q_{N}^{k+1}-q_{N-1}^{k+1}\right)+q_{N}^{k+1}\right] \\
z_{N+1}^{k+1} & =\left[\left(z_{N}^{k+1}-z_{N-1}^{k+1}\right)+z_{N}^{k+1}\right]
\end{aligned}
$$

\section{Data used in the present study}

\subsection{Experimental set-up and data collection}

The description of experimental set-up, detailed procedure of data collection; and salient features of data being used in the present study are described in the following paragraphs.

3.1a Experimental flume: The series of experimental runs were undertaken in a straight, recirculating tilting flume having $15 \mathrm{~m}$ length, $0.89 \mathrm{~m}$ width and $0.6 \mathrm{~m}$ height (see figure 3) at Advanced Hydraulics Laboratory of Civil Engineering Department at SVNIT, Surat, India. The measuring test section starts at $5.0 \mathrm{~m}$ distance from inlet to the flume, and consists of steel frame with side glass wall of $6 \mathrm{~m}$ length. The complete experimental set-up for measurement of bed and water surface profiles including different components of tilting flume, viz., centrifugal pumps, recirculating pipe, digital flow meter, control panel board, 
screw jack drive with DC motor, flow regulating valve, inlet, flow straightener, test section, sediment feeder with conveyor belt, pointer gauge with point and flat bottom mounted on carrier trolley, sliding and lifting arrangement for sediment trap, water level sensor, tail gate operated by lever arm at downstream end, volumetric tank, and downstream reservoir, are shown in figure 3 . The discharge into the channel is supplied from downstream reservoir, having 45,000 litres capacity, using two 7.5 HP centrifugal pumps connected with $25 \mathrm{~cm}$ diameter recirculating pipe. Flow rate is measured by a digital flow meter (VATS JT121 make) having capacity of 24 LPS to 240 LPS, with accuracy of $\pm 1 \%$. The discharge flowing into the channel, could also be measured volumetrically with the help of volumetric tank provided at the downstream end of the channel. Water levels and bed levels were measured at $1 \mathrm{~m}$ interval using pointer gauge and a gauge having circular flat bottom, respectively with least count of $0.1 \mathrm{~mm}$ throughout length of the test section. Five numbers of water level sensors were also installed to record the water levels covering the entire working section of the flume. Such observations were recorded from a digital panel board, installed at upstream end of the channel.

The turbulent flow was fully developed by laying coarse gravel bed of $16 \mathrm{~mm}$ to $32 \mathrm{~mm}$, over a $3 \mathrm{~m}$ length at upstream end of test section. The sediment feeder, having a hopper and a conveyor belt, was used for continuous feeding of sediment at the upstream end of the test section over the entire width of the channel. The sediment trap section, having $0.75 \mathrm{~m}$ width, $2.7 \mathrm{~m}$ length and $1.2 \mathrm{~m}$ height, containing two box type sediment samplers, having $0.75 \mathrm{~m}$ width, $0.89 \mathrm{~m}$ length and $0.4 \mathrm{~m}$ height, with sliding and lifting arrangement, were used for continuous sampling of bed load without disturbing the flow. An electronic weighing machine with $0.01 \mathrm{~g}$ least count and an automatic sieve shaker with series of 0.0625 to $45.0 \mathrm{~mm}$ sieves at 0.5 unit interval were use for sieve size analysis of bed material.

3.1b Preparation of fluvial channel bed: The sediments used for experiments were collected from the bed of the Tapi river, India, having sediment sizes up to $64 \mathrm{~mm}$ at the sampling site. The sediments, obtained from the river source, were sieved into different size ranges of six fractions. The uniform sediment fractions, obtained after sieving, were mixed into the required proportions to get the sediment mixtures of designed gradation and nonuniformity. The grain size distributions of nonuniform sediments used in the present study are shown in figure 4 . The range of flow and sediment of characteristics used in the study are included in table 1. In table $1, d_{a}, \sigma_{g}$ and $\mathrm{M}$ represent arithmetic mean size, geometric standard deviation and
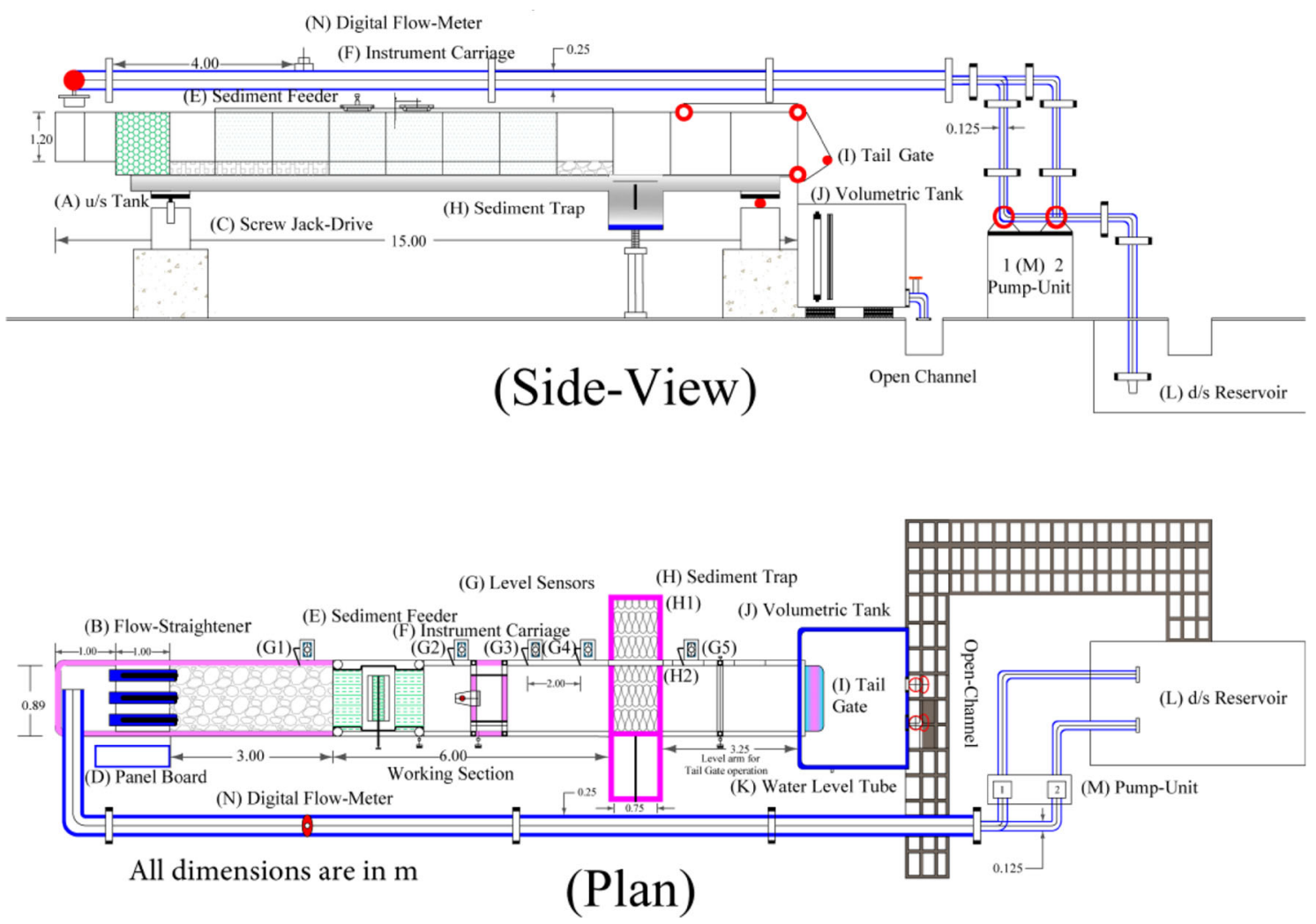

Figure 3. Layout plan of experimental flume set-up installed at SVNIT, Surat, India. 


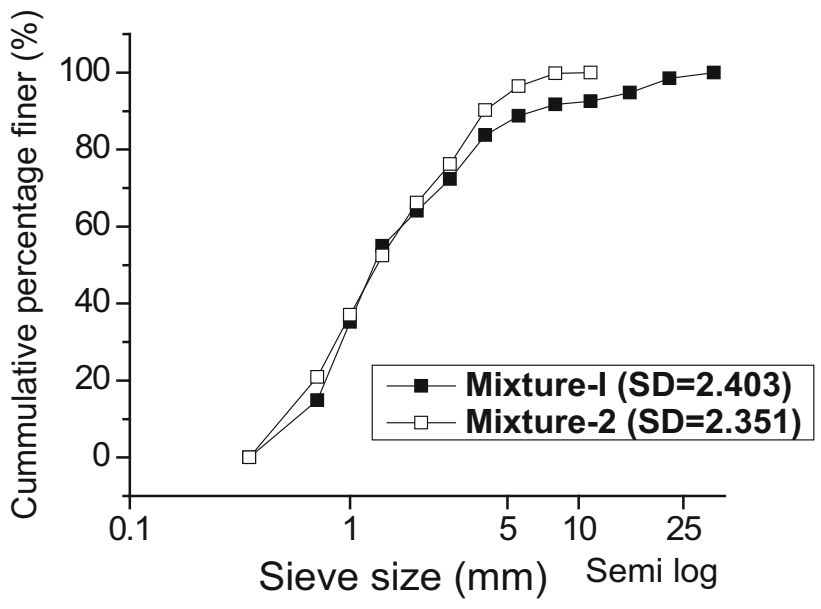

Figure 4. Grain size distribution of sediment mixtures used in the present study.

Kramer's uniformity co-efficient respectively, see Eqs. (26, 29).

$$
d_{a}=\sum_{j=1}^{n} d_{j} \cdot f_{j}=\frac{\sum_{j=1}^{n} d_{j} \cdot \Delta p_{j}}{100}
$$

Here, $\Delta p_{j}=P_{2}-P_{1}$; where $P_{1}$ and $P_{2}$ correspond to percentage finer, by weight, for the sieve sizes $d_{1}$ and $d_{2}$, and $d_{i}=\left(d_{1} \cdot d_{2}\right)^{0.5}$ is geometric mean size of size range $\left(d_{1}-d_{2}\right) ; d_{g}$ is geometric mean size of sediment mixture can be defined as

$$
\log d_{g}=\frac{1}{100} \sum \Delta p_{j} \cdot \log d_{j}
$$

Geometric standard deviation of sediment mixture $\left(\sigma_{g}\right)$ is given by

$$
\sigma_{g}=\sqrt{d_{84.1} / d_{15.9}}
$$

where, $d_{84.1}$ and $d_{15.9}$ are sizes such that $84 \%$ and $16 \%$ of particles are respectively finer, by weight, than these sizes.

Kramer's uniformity coefficient (M) is defined as

$$
M=\frac{\sum_{0}^{50} d_{j} \cdot f_{j}}{\sum_{50}^{100} d_{j} \cdot f_{j}}=\frac{\sum_{0}^{50} d_{j} \cdot \Delta p_{j}}{\sum_{50}^{100} d_{j} \cdot \Delta p_{j}}
$$

The sediment used for experimental work was filled up in the test section of the flume carefully to avoid segregation of the bed material. The prepared bed of sediment layer ( $0.07 \mathrm{~m}$ thick) was levelled carefully to achieve uniform longitudinal slope throughout the test section

3.1c Development and measurement of aggrading bed profiles: For each experimental run, initially, a small discharge was allowed to enter into the flume, and uniform flow condition was established by operating the tail gate. The discharge was increased in small increments by operating the inlet valve, and uniform flow conditions were 


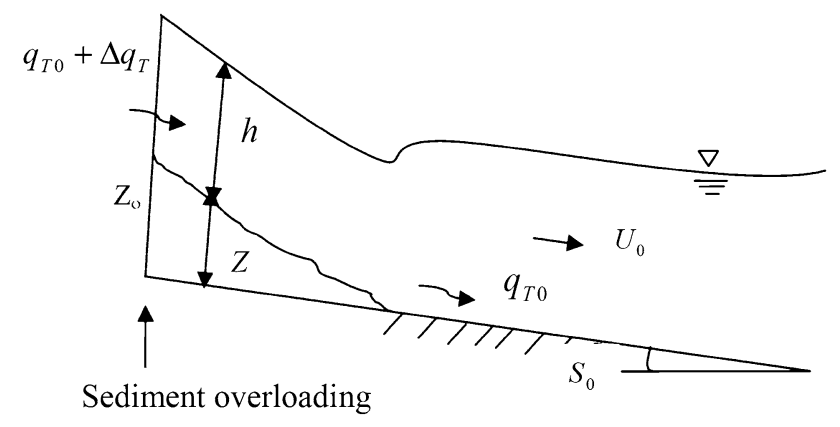

Figure 5. Definition sketch of bed-level changes due to sediment overloading.

maintained for each discharge in the channel. The increase in discharges was continued till adequate measurements of sediments were observed in the channel bed. The transported bed material were sampled at regular intervals ( 15 to 30 min depending on flow conditions) using sediment sampler as described in preceding section. The transported materials were brought back to upstream to feed the same through sediment feeder to maintain the equilibrium sediment transport conditions in the system. The equilibrium sediment transport condition was said to be achieved as and when the weights of three consecutive samples, collected for fixed duration, were of the same magnitude.

The sediment supply rate to the system was increased to a predetermined value varied from 1.50 to 6.50 times of equilibrium sediment discharge, by continuously feeding excess sediment at the upstream end using sediment feeder. Due to excess feeding of sediment, the sediments started depositing in upstream end, and aggrading profiles were formed (see definition sketch, figure 5). The bed and water surface profiles were measured simultaneously at $1 \mathrm{~m}$ interval in the working section using a gauge with flat bottom and a pointer gauge at $15 \mathrm{~min}$ intervals just after the commencement of aggrading profile. The measurement of transient profiles continued till the aggrading bed front likely to reach at the end of working section. At the end of the test run, bed was allowed to drain and become dry. The sediments in the channel bed were mixed thoroughly to maintain initial conditions in the channel for next experiment. Here, it is worth mention that size of available sediments in the flume bed, and flow conditions were such that only bed load were transported during the experiments. The complete experimental data collected in the present investigation on nonuniform sediments; and bed and water surface profiles are included in Appendix A.

\section{Performance of numerical model for nonuniform sediment bed}

The bed and water surface profiles for the flow conditions, as described in table 2, were computed as per the methodology described in figure 2 for nonuniform sediment beds. The developed numerical model has been used to simulate the transient bed and water levels corresponding to $15,60,90,110$ and $120 \mathrm{~min}$ timings from the beginning of overloading in nonuniform sediment beds $\left(\mathrm{M}_{1}\right.$ and $\mathrm{M}_{2}$ ). The performance of the model with corresponding observed bed and water levels using statistical indices are included in table 2.

The scatter plots for the data reported in table 2 are not included due to concern on large length of the manuscript.

\section{Results and discussions}

From table 2, it is apparent that root mean square error (RMSE) and mean absolute standard error (MASE) between observed and simulated bed levels are within 0.87 . On other hand, root mean square error (RMSE) for computed water levels are within 0.45 . The performance of numerical model in prediction of bed level of nonuniform sediment beds is in variably satisfactory for the whole range of data. The prediction of water levels is better than corresponding prediction of bed levels due to inherent limitation of semi-coupled models vis-à-vis coupled models, in coupling the sediment continuity equation with flow equations. The performance of numerical model, for the same period of simulations and sediment overloading rates, is similar for both the sediments as the sediment transport laws, implemented in the proposed numerical model, are applicable even for extreme nonuniform sediments (Kramer's uniformity coefficient, $M \geq 0.05$ ). From table 2 , it is apparent that numerical model gives similar results, for water level and bed level predictions, up to sediment overloading rate $\Delta q_{s} / q_{s} \leq 4.0$ (refer table A1 in Appendix A for details of overloading rates). However, the performance of the model becomes inferior for larger sediment overloading rates $\left(\mathrm{M}_{2}-1, \Delta q_{s} / q_{s} \leq 6.0\right)$, may be due to inability of the model to capture steep front of aggrading profile.

The performance of the proposed numerical model, based on nonuniform sediment transport functions, has been compared with the numerical model while considering the uniform sediment transport function for same sediments.

Proposed numerical model for bed level prediction, based on existing uniform sediment functions, was applied for experimental data collected by Andharia [31]. The numerical model using Karim and Kennedy [32] sediment transport function was found to be best performing vis-a-vis other sediment transport functions of uniform sediments [31]. The average size of nonuniform sediments have been used for computation of sediment transport rates while using Karim and Kennedy [32] sediment transport function in the numerical model. The proposed numerical model, based on nonuniform sediment transport function, vis-vis uniform sediment transport function is compared for M-1 sediment mixture, see Table 3 and figure 6. From Table 3 and figure 6 , it is evident that the model based on nonuniform sediment 
Table 2. Performance of numerical model developed for nonuniform sediments used in the present study.

\begin{tabular}{|c|c|c|c|c|c|c|c|c|c|c|c|c|}
\hline \multirow[b]{2}{*}{ Experimental Runs } & \multirow[b]{2}{*}{ Parameter } & \multirow[b]{2}{*}{ Performance indices } & \multicolumn{10}{|c|}{ Time (Minutes) } \\
\hline & & & 15 & 30 & 45 & 60 & 75 & 90 & 110 & 120 & 180 & 240 \\
\hline \multirow[t]{4}{*}{$\mathrm{M}_{1}-2$} & $\mathrm{BL}^{*}$ & RMSE $(\mathrm{cm})$ & 0.15 & - & - & 0.23 & - & 0.20 & 0.20 & 0.50 & - & - \\
\hline & & MASE (cm) & 0.13 & - & - & 0.18 & - & 0.19 & 0.12 & 0.20 & - & - \\
\hline & $\mathrm{WL}^{*}$ & RMSE (cm) & 0.22 & - & - & 0.27 & - & 0.18 & 0.25 & 0.34 & - & - \\
\hline & & MASE (cm) & 0.19 & - & - & 0.20 & - & 0.16 & 0.39 & 0.30 & - & - \\
\hline \multirow[t]{4}{*}{$M_{1}-3$} & $\mathrm{BL}$ & RMSE (cm) & 0.07 & 0.11 & 0.14 & 0.29 & - & - & - & - & - & - \\
\hline & & $\operatorname{MASE}(\mathrm{cm})$ & 0.03 & 0.085 & 0.105 & 0.24 & - & - & - & - & - & - \\
\hline & WL & RMSE (cm) & 0.06 & 0.23 & 0.13 & 0.18 & - & - & - & - & - & - \\
\hline & & MASE $(\mathrm{cm})$ & 0.02 & 0.198 & 0.11 & 0.12 & - & - & - & - & - & - \\
\hline \multirow[t]{4}{*}{$M_{1}-4$} & $\mathrm{BL}$ & RMSE (cm) & 0.23 & - & - & 0.25 & - & - & - & 0.22 & 0.15 & 0.87 \\
\hline & & MASE (cm) & 0.18 & - & - & 0.17 & - & - & - & 0.18 & 0.10 & 0.69 \\
\hline & WL & RMSE (cm) & 0.18 & - & - & 0.16 & - & - & - & 0.2 & 0.29 & 0.20 \\
\hline & & MASE $(\mathrm{cm})$ & 0.138 & - & - & 0.11 & - & - & - & 0.16 & 0.20 & 0.18 \\
\hline \multirow[t]{4}{*}{$\mathrm{M}_{2}-1$} & BL & RMSE (cm) & 0.27 & 0.38 & - & 0.37 & 0.50 & - & - & - & - & - \\
\hline & & MASE (cm) & 0.25 & 0.36 & - & 0.34 & 0.43 & - & - & - & - & - \\
\hline & WL & RMSE (cm) & 0.26 & 0.276 & - & 0.4 & 0.45 & - & - & - & - & - \\
\hline & & MASE $(\mathrm{cm})$ & 0.23 & 0.20 & - & 0.32 & 0.30 & - & - & - & - & - \\
\hline \multirow[t]{4}{*}{$\mathrm{M}_{2}-2$} & BL & RMSE (cm) & 0.11 & 0.22 & 0.15 & 0.27 & - & - & - & - & - & - \\
\hline & & MASE (cm) & 0.07 & 0.18 & 0.12 & 0.22 & - & - & - & - & - & - \\
\hline & WL & RMSE (cm) & 0.2 & 0.3 & 0.24 & 0.25 & - & - & - & - & - & - \\
\hline & & MASE (cm) & 0.16 & 0.26 & 0.20 & 0.19 & - & - & - & - & - & - \\
\hline \multirow[t]{4}{*}{$M_{2}-3$} & BL & RMSE (cm) & 0.19 & 0.31 & 0.30 & 0.24 & - & - & - & - & - & - \\
\hline & & MASE (cm) & 0.13 & 0.24 & 0.23 & 0.20 & - & - & - & - & - & - \\
\hline & WL & RMSE (cm) & 0.20 & 0.22 & 0.30 & 0.19 & - & - & - & - & - & - \\
\hline & & MASE (cm) & 0.129 & 0.19 & 0.26 & 0.13 & - & - & - & - & - & - \\
\hline
\end{tabular}

transport functions performs better than the model based on uniform sediment transport function, particularly for higher transition period. As the sediments in nature are invariably nonuniform in character, the numerical model developed in the present study could be helpful in prediction of bed level variations of aggrading field channels.

\section{Conclusions and future work}

A numerical model, based on one-dimensional de Saint_Venant equations and Exner's sediment continuity equation, is developed for prediction of bed and water levels

Table 3. Statistical performance of numerical models based on uniform and nonuniform sediments using statistical performance indices.

\begin{tabular}{|c|c|c|c|c|c|c|c|c|}
\hline \multirow{3}{*}{$\begin{array}{l}\text { Run } \\
\text { Transient } \\
\text { profiles } \\
\text { Time }\end{array}$} & \multicolumn{4}{|c|}{$\begin{array}{l}\text { Uniform Sediments } \\
\quad\left(\text { Run } \mathrm{M}_{1}-4\right)\end{array}$} & \multicolumn{4}{|c|}{$\begin{array}{l}\text { Nonuniform Sediments } \\
\left.\text { (Run } \mathrm{M}_{1}-4\right)\end{array}$} \\
\hline & \multicolumn{2}{|c|}{$\begin{array}{c}\text { RMSE } \\
(\mathrm{cm}) \sum_{2} \\
\sqrt{ }(\mathrm{M}-\mathrm{P})^{2} / \mathrm{n} \\
\end{array}$} & \multicolumn{2}{|c|}{$\begin{array}{c}\text { MASE } \\
(\mathrm{cm}) \\
\sum \mathrm{M}-\mathrm{Pl} / \mathrm{n}\end{array}$} & \multicolumn{2}{|c|}{$\begin{array}{l}\text { RMSE } \\
(\mathrm{cm})\end{array}$} & \multicolumn{2}{|c|}{$\begin{array}{c}\text { MASE } \\
(\mathrm{cm}) \\
\sum \mid \mathrm{M}-\mathrm{Pl} / \mathrm{n}\end{array}$} \\
\hline & BL & WL & BL & WL & BL & WL & $\mathrm{BL}$ & WL \\
\hline $60 \mathrm{mi}$ & 0.25 & 0.26 & 0.17 & 0.21 & 0.25 & 0.16 & 0.17 & 0.11 \\
\hline $180 \mathrm{~min}$ & 0.38 & 0.36 & 0.29 & 0.28 & 0.15 & 0.29 & 0.10 & 0.20 \\
\hline
\end{tabular}

variations in aggrading alluvial channels. The 'Active bed layer' theory given by [10] has been used to derive the grain sorting equation from sediment continuity equation for different size classes for channel bed made up of nonuniform sediments. The key conclusions arrived from the study are summarized.

(a) A one-dimensional numerical model is developed for prediction of bed level variations in aggrading channel due to sediment overloading in nonuniform sediments bed.

(b) Series of experimental investigations have been undertaken to measure bed and water level variations due to overloading of alluvial channel with sediment bed made up of nonuniform sediment mixtures with Kramer's uniformity coefficients (M) of 0.177 (mixture-1) and 0.276 (mixture-2).

(c) The numerical model developed based on fractional bed load transport and suspended load transport rates, i.e., Patel and Ranga Raju [25] and Samaga et al. [26, 27] have been validated with the observed data in the present study on aggrading channels. The model has been found to be satisfactory in prediction of bed and water level variations of aggrading channels.

(d) The statistical performance of the numerical model developed for nonuniform sediment beds has also been compared with the numerical model based on uniform sediment transport function. The comparative 


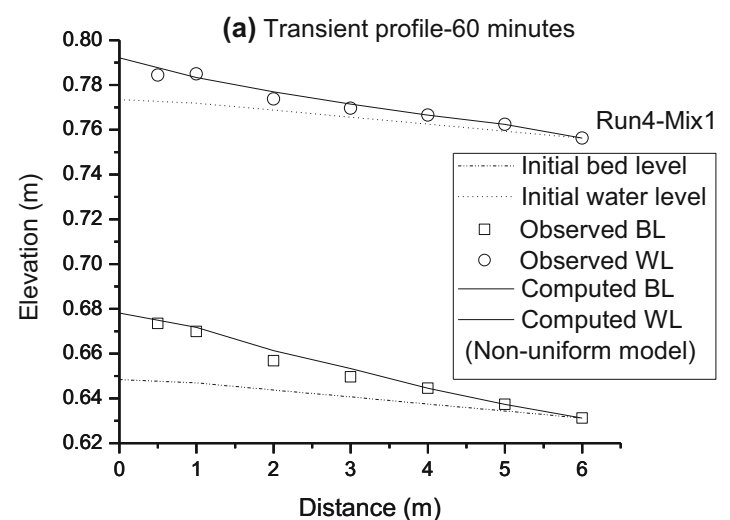

Nonuniform Sediments (60 min)

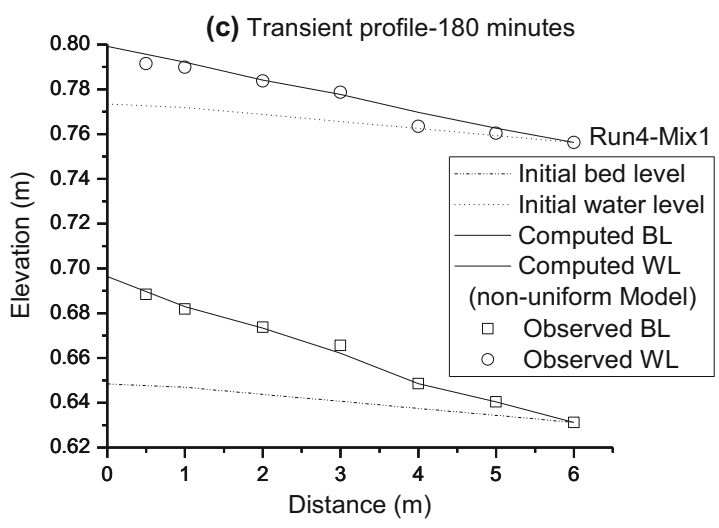

Nonuniform Sediments (180 min)

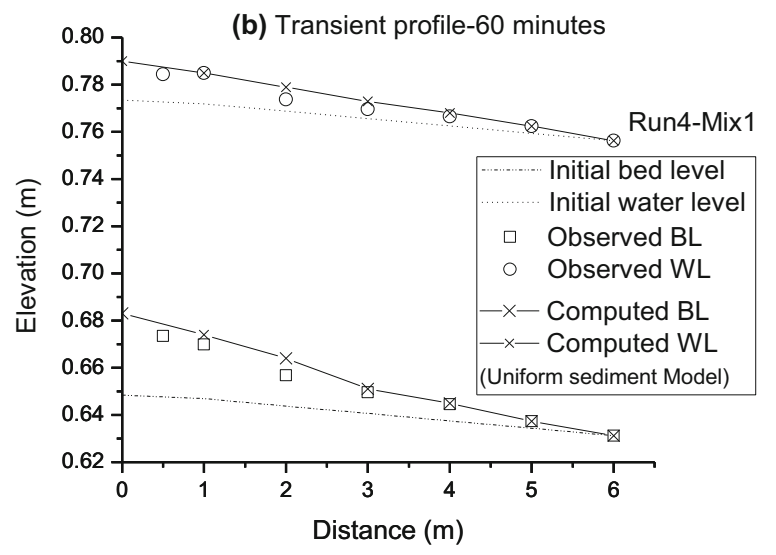

Uniform Sediment (60 min)

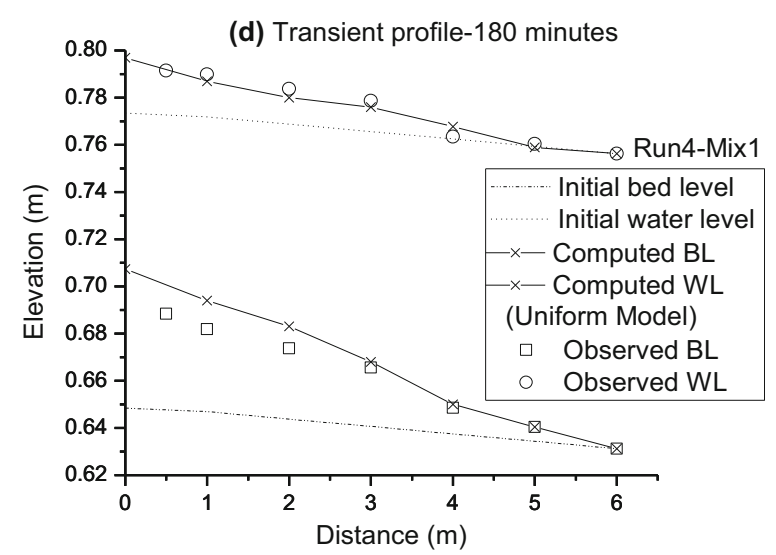

Uniform Sediment (180 min)

Figure 6. Performance assessment of numerical models developed for nonuniform and uniform sediments (run $\mathrm{M}_{1}-4$ ).

performance clearly highlights the importance of numerical model based on nonuniform sediments transport functions over the model based on uniform sediment transport functions.

The present study can be explored further for two-dimensional depth averaged numerical model for unsteady flow in open channels using finite difference or finite volume approaches. The model developed for nonuniform sediments is required to be validated for more sets of data from field channels. Also, the model developed for noncohesive sediments is required to be implemented for cohesive sediments.

\section{Acknowledgements}

The authors would like to thank the Department of Science and Technology (DST), New Delhi, Government of India, for the financial support for installing the flume facilities through the Research Project "Erosion of nonuniform unimodal and bimodal sediments" with project Grant No. SR/S3/MERC/015/2009.

\section{Notation}

$B_{O} \quad$ width of channel at initial time line, $\mathrm{t}=0$

$C_{n} \quad$ Courant number

$d \quad$ diameter of sediment particle

$d_{a} \quad$ arithmetic mean diameter of sediment particle $(\mathrm{mm})$

$d_{g} \quad$ geometric mean size of sediment mixture

$d_{j} \quad$ particular size fraction of sediment mixture; geometric mean size of sieve sizes $d_{1}$ and $d_{2}$

$d_{15.9}$ sizes such that $15.9 \%$ of particles are finer, by weight, than these sizes

$d_{84.1}$ sizes such that $84.1 \%$ of particles are finer, by weight, than these sizes

$d_{90} \quad$ sediment size such that $90 \%$ of the material, by weight, is finer than this size,

$f_{i} \quad$ probability of occurrence of size $d_{i}$ Under consideration

F flux vector

$g$ acceleration due to gravity 
$h \quad$ depth of flow

$h_{0} \quad$ initial flow depth

$L \quad$ length of channel

M Kramer's uniformity coefficient

$M_{1}$ represents sediment mixture 1 of the present study

$\mathrm{M}_{2}$ represents sediment mixture 2 of the present study

$n \quad$ Manning's roughness co-efficient or total number of observations

$p \quad$ porosity of bed layer

$p_{j} \quad$ percentage of sediment size fraction, $d_{j}$, in the $A B L$

$\Delta p_{j} \quad$ change in percentage weight corresponding to size $d_{j}$

$P_{1} \quad$ percentage finer by weight for sieve size $d_{1}$

$q \quad$ water discharge per unit width

$q_{0} \quad$ initial uniform flow discharge

$q_{T O} \quad$ rate of equilibrium sediment discharge per unit width of channel

$\Delta q_{T} \quad$ increase in sediment discharge due to overloading

$q_{B} \quad$ rate of bed load transported per unit width, by weight, $(\mathrm{N} / \mathrm{s} / \mathrm{m})$

$q_{T}$ rate of total sediment transport by weight per unit width of channel (N/s/m), $\left(q_{T}=q_{B}+q_{S}\right)$

$q_{\text {Tin }} \quad$ sediment overloading rate at upstream fictitious node $\left(q_{T 0}+\Delta q_{T}\right)$

$q_{B j} \quad$ fractional bed load transport rates of $j^{\text {th }}$ size fraction

$q_{s j} \quad$ fractional suspended load transport rates of $j^{\text {th }}$ size fraction

Q flow discharge $\left(\mathrm{m}^{3} / \mathrm{s}\right)$

$r \quad$ total number of size fractions

$S_{O} \quad$ longitudinal slope of the channel at $\mathrm{t}=0$

S source term vector

$S_{f} \quad$ friction slope

$t \quad$ time scale of computational grid

$\mathrm{t}_{\text {last }} \quad$ last computational step

$\Delta t \quad$ temporal step in y direction

$T_{b} \quad$ thickness of active bed layer

$\mathrm{U}$ average flow velocity

U dependent variable vector

$U \quad$ variable representing the unknown (h, q and $\mathrm{z}$ ) for finite difference discretization in present
$V_{i, j}^{k} \quad$ total volume of any particle size, $d_{j}$, present in the active layer per unit length of the channel, at $i^{\text {th }}$ space node and $k^{\text {th }}$ time line

$x \quad$ distance along the channel

$\Delta x \quad$ space interval in computational grid (m)/distance increment

$z_{0} \quad$ initial bed level

$z \quad$ bed elevation

$\mathrm{Z}_{0} \quad$ hydraulic roughness parameter

$z_{i+1}^{k+1}$ bed level at computational node $\mathrm{i}+1$ for unknown time level $k+1$ for each time step

\section{Greek symbol}

$\sigma_{g} \quad$ geometric standard deviations of bed material

$\tau_{0} \quad$ mean shear stress $\left(\mathrm{N} / \mathrm{m}^{2}\right)$

$\tau_{0 c} \quad$ critical shear stress $\left(\mathrm{N} / \mathrm{m}^{2}\right)$

$\varepsilon \quad$ residual error

\section{Superscript and subscript}

$i \quad$ denotes the space node

$j \quad$ denotes size fractions in sediment mixture

$k$ denotes the time node

$o$ stands for initial values

* $\quad$ superscript values of the variables after the predictor steps at the unknown time $\mathrm{k}+1$ level

** superscript values of the variables after the corrector steps at the unknown time $\mathrm{k}+1$ level
Abbreviations
ABL active bed layer
BL bed level
FCM fully coupled model
MASE mean absolute standard error
RMSE root mean square error
SD standard deviation
WL water level

\section{Appendix A: Experimental data collected from the present study}

See Tables A1 and A2. 


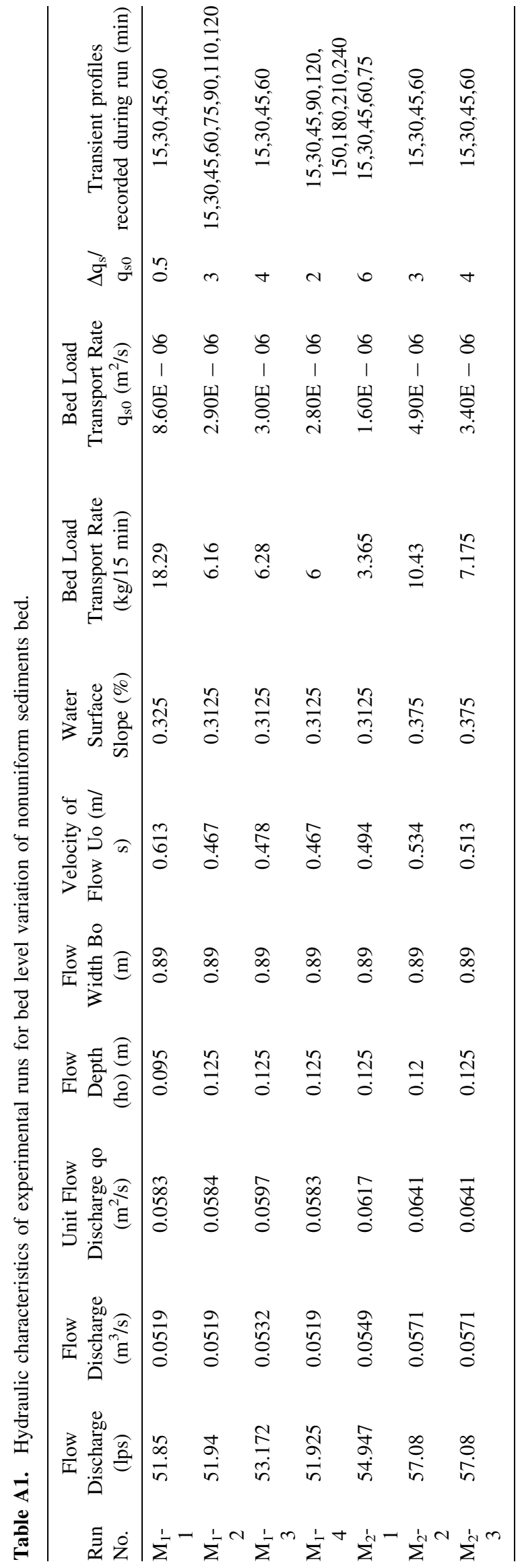




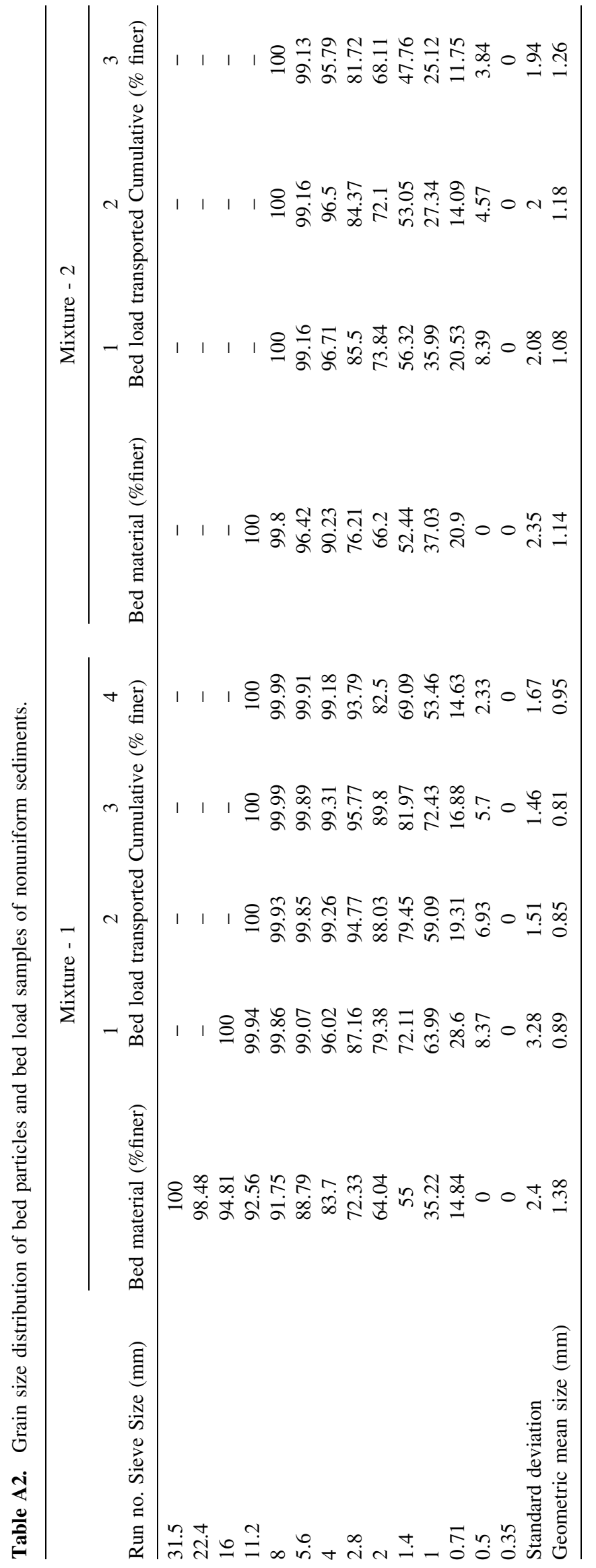




\section{References}

[1] Rahuel J L, Holly F M, Chollet J P Belludy P and Yang G 1989 Modelling of river bed evolution for bed load sediment mixtures. J. Hydraulic Eng. ASCE 115(11): 1521-1542

[2] Holly F, Yang J, Schwarz P, Schaefer J, Hsu S and Einhellig R 1993 Numerical simulation of unsteady water and sediment movement in multiply connected networks of mobilebed channels. IIHR Report No 343. Iowa Institute of Hydraulic Research The University of Iowa, Iowa

[3] Saiedi S 1997 Coupled modeling of alluvial flows. J. Hydraulic Eng. ASCE 123 (5): 440-446

[4] Kassem A M and Chaudhry M H 1998 Comparison of coupled and semicoupled numerical models for alluvial channels. J. Hydraulic Eng. ASCE 124(8): 794-802

[5] Cao Z, Pender G, Wallis S and Carling P 2004 Computational dam-break hydraulics over erodible sediment bed. $J$. Hydraulic Eng. ASCE 130(7): 689-703

[6] Ferguson R and Church M 2009 A critical perspective on 1-D modeling of river processes: Gravel load and aggradation in lower Fraser River. Water Resources Res. 45: W11424, https://doi.org/10.1029/2009WR007740

[7] Termini D 2011b Bed scouring downstream of hydraulic structures under steady flow conditions: Experimental analysis of space and time scales and implications for mathematical modeling. Catena 84 Elsevier BV, 125-135, https:// doi.org/10.1016/j.catena.2010.10.008

[8] Termini D 2014 Nonuniform sediment transport estimation in non-equilibrium situations: case studies. CCWI2013 Procedia Engineering. 70: 1639-1648

[9] Dey S 2014 Fluvial hydrodynamics, Hydrodynamics and sediment transport phenomena, Heidelberg, Newyork, Dordrecht, London:Springer

[10] Borah D K, Alonso C V and Prasad S N 1982a Routing graded sediment in stream formulations. J. Hydraulic Eng. ASCE 108(12): 1486-1503

[11] Ashida K and Michiue M 1971 An investigation of river bed degradation downstream of a dam. In: Proc. 14th Congress of IAHR, Paris France, 3: 247-253

[12] Lyn D A 1987 Unsteady sediment transport modeling. J. Hydraulic Eng. ASCE 113(1): 1-15

[13] Lyn D A and Goodwin S M 1987 Stability of a general Preissmann scheme. J. Hydraulic Eng. ASCE 113(1): 16-28

[14] Meyer P E and Muller R 1948 Formulas for bed load transport. In: Proceeding 2nd Congress of IAHR, Sweden, Appendix-2: 39-64

[15] Holly F and Rahuel J 1990a New numerical physical framework for mobile-bed modelling part I: numerical and physical principles. J. Hydraulic Res. 28(4): 401-416

[16] Holly F and Rahuel J 1990b New numerical physical framework for mobile-bed modelling part II: test applications. J. Hydraulic Res. 28(4): 545-564
[17] Alcrudo F, Garcia-Navarro P and Saviron J M 1992 Flux difference spilitting for 1D open channel flow equations. Int. J. Numerical Methods Fluids. 14: 1009-1018

[18] Correia L R P, Krishnappan B G and Graf W H 1992 Fully coupled unsteady mobile boundary flow model. J. Hydraulic Eng. Proc. ASCE 118(3): 476-494

[19] Cui Y, Parker G and Paola C 1996 Numerical simulation of aggradation and downstream fining. J. Hydraulic Res. 34(2): 195-204

[20] Saiedi S 1993 Experience in design of a laboratory flume for sediment studies. Int. J. Sediment Res. 8(3): 89-101

[21] Singh A K, Kothyari U C and Ranga Raju K G 2004 Rapidly varying transient flows in alluvial rivers. J. Hydraulic Res. IAHR 42(5): 473-486

[22] Wu W, Vieira D A and Wang S S Y 2004 1D numerical model for nonuniform sediment transport under unsteady flows in channel networks. J. Hydraulic Eng. 130(9): 914-923

[23] Pontillo M, Schmocker L, Greco M and Hager W H 2010 1D numerical evaluation of dike erosion due to overtopping. $J$. Hydraulic Res. 48(5): 573-582

[24] Bhallamudi S M and Chaudhry H M 1991 Numerical modeling of aggradation and degradation in alluvial channel. $J$. Hydraulic Eng. ASCE 117(9): 1145-1164

[25] Patel P L and Ranga Raju K G 1996 Fraction wise Calculation of Bed Load Transport. J. Hydraulic Res. IAHR 34(3): 363-379

[26] Samaga B R, Ranga Raju K G and Garde R J 1986 Bed load transport of sediment mixtures. J. Hydraulic Eng. 112(11): $1003-1018$

[27] Samaga B R, Ranga Raju K G and Garde R J 1986 Suspended load transport of sediment mixtures. J. Hydraulic Eng. 112(11): 1019-1035

[28] MacCormack R W 1976 An efficient numerical method for solving the time dependent compressible Navier-Stokes equations at high Reynolds number. Computing Applied Mech. ASME A77-46133: 21-59

[29] Garcia-Navarro P, Alcrudo F and Saviron J M 1992 1-D Open-channel flow simulation using TVD-MacCormack scheme. J. Hydraulic Eng. ASCE 118(10): 1359-1372

[30] Alcrudo F and Garcia-Navarro P 1993 A high resolution Godunov-type scheme in finite volumes for the 2D shallowwater equations. International Journal of Numerical Methods in Fluids. 16(6): 489-505

[31] Andharia B R 2017 Prediction of flow resistance and bed level variations in alluvial channels. Ph.D. Thesis. Departments of Civil Engineering, S. V. National Institute of Technology, Surat, India

[32] Karim M F and Kennedy J F 1983 Computer based predictors for sediment discharge and friction factor of alluvial streams. In: Proc. of 2nd Int. Symposium on River Sedimentation, Oct.-Nov., Nanjing, China 